\title{
Experimental research of oil pump for a compression-ignition aircraft engine
}

The paper presents an analysis of the constructions of oil pumps for an aircraft compression ignition engine. It is a two-stroke liquidcooled engine with a power of $100 \mathrm{~kW}$. The system has 3 cylinders and 6 opposed pistons. The paper estimates the required oil pump capacity to make the engine components well-lubricated. Next, automotive oil pumps for diesel engines are analyzed to select a correct pump for aircraft diesel engine applications. Three pump constructions of different constructions and dimensions of a rotor were selected. A measurement bench was designed and built to test these oil pumps in the range of pump shaft speeds from 0 to $4500 \mathrm{rpm}$ and volumetric flow rate up to $150 \mathrm{l} / \mathrm{min}$. The bench also enables stabilization of oil temperature at the required level within the range from 30 to $120^{\circ} \mathrm{C}$. In addition, flow resistance through engine slide bearings was simulated by changing the position of a throttling valve at the pump output to regulate pressure in the range of 0-700 $\mathrm{kPa}$. The obtained capacity characteristics of individual pumps versus on oil pressure and temperature allowed us to find an appropriate oil pump to make individual engine nodes well-lubricated.

Key words: diesel engine, opposed piston engine, aircraft propulsion system, oil system, oil pump

\section{Introduction}

The oil pump is the key element of the internal combustion engine lubrication system. Its main function is to supply lubricating oil to various rotating and sliding parts of the engine to prevent engine wear and overheating. There are oil pumps with external and internal gearing called gerotor pumps. Gerotor pumps have epicycloidal wheels.

To select an oil pump for a specific engine, you should know the number of lubrication nodes, engine load and a type of oil system, i.e. open or closed. You should also bear in mind whether oil will flow through a cooler. The viscosity of oil and clearance are also important. Oil flow and pressure generated by the oil pump must be well matched to a given purpose. To drive an oil pump, you need power from an engine shaft, so the larger the flow and pressure in a pump, the more power is taken from an engine. Most engines do not require too high oil pressure at idle.

Speeds of rotary oil pumps can be limited by, e.g. cavitation. The authors of the paper [1] carried out some model tests of an oil pump for a motorcycle engine considering the cavitation phenomenon. The model was validated on a test stand. The tests were carried out for different pump speeds at an oil temperature of $100^{\circ} \mathrm{C}$.

Internal and external oil leaks in the oil pump are further factors that can adversely affect oil flow and pressure. Certainly, the smaller clearance is, the higher pumping efficiency. Clearance, in turn, compensates for thermal expansion when a pump and oil heat up to high temperatures.

Increased oil temperature is more dependent on engine speed than load. Oil pressure, on the other hand, hardly affects the increase in lubricating oil temperature. It was observed, however, that it is fundamental to maintain a minimum pressure of oil that is supplied to a bearing because a rapid increased in a temperature of a slide bearing occurs when lubrication at low supply pressures is insufficient. Conversely, friction losses in a crank system do not depend on pressure in an oil system [5]. Pressurecontrolled pumps are increasingly being used in lubrication systems.
The authors of work [4] developed a 3D model of an oil pump which enables the selection of appropriate geometrical parameters of the pump for automotive and aviation applications.

Both 1- and 3-dimensional simulations of pump were discussed in the works $[2,3,7]$. The authors demonstrated there, e.g. the use of 3-dimensional methods on gerotor oil pumps to verify 1-dimensional computations for larger parts of the governing oil system, to explain the test rig and engine experiments and to optimize the gerotor itself. Vane oil pumps and gerotor pumps were researched and these results are compared with the existing experimental data.

On the market, there are also available stands to measure pump capacity and its other parameters, e.g. ATA (Advanced Test \& Automation) offers stands and tests of oil and water pumps for the automotive industry.

The first part of this paper presents the principles of a lubrication system of an aircraft opposed-piston compression ignition engine. Then, the requirements for the maximum volumetric flow rate are determined. Next, several pumps for compression ignition engines with the number of lubricating points similar to the designed aircraft engine are selected for the tests performed on a special test stand. The research allowed us to create maps of individual pumps and to select the pump for the designed engine.

\section{Aircraft compression ignition engine oil pump}

\subsection{Engine oil system}

The oil pump is designed for the new construction of aircraft engines with compression-ignition and power of $100 \mathrm{~kW}$. The liquid-cooled engine has 3 cylinders and 6 opposed-pistons. The engine with a capacity of $1.5 \mathrm{dm}^{3}$ is charged by means of a mechanical compressor.

A lubrication system in the planned aircraft diesel opposite piston engine (OPE) is a forced lubrication system with a dry oil sump (Fig. 1). The system is now equipped with two pressure pumps in a housing fixed to an engine block. The pumps are driven directly from engine crankshafts. The pump sucks oil from a tank by means of a heat exchanger and presses it through an oil filter to an oil main in the 
engine block from where the oil is distributed to individual lubrication nodes. It is expected that the oil from the engine block will be pumped into the tank by high pressure generated by blows to a crankcase through pipes in the lower part of the oil sump. No additional oil pump is applied to dry the system. Such a solution can be found, among others, in Rotax 912/914 engines where a drying pump is the only element to suck oil from a charge compressor, whereas oil from the oil sump is pumped into an external tank by blowgenerated high pressure in the engine block.

The theoretical flow rate of this pump is about $40 \mathrm{l} / \mathrm{min}$ for $4500 \mathrm{rpm}$, which gives the total flow rate of the both pumps, i.e. about $80 \mathrm{l} / \mathrm{min}$. Regarding construction factors, the new type of engine will have a single oil pump with a flow rate similar to that of today's pumps to make the engine correctly lubricated and cooled.

According to the authors of the work, the [6] unit output of oil in the engine, depending on the $\mathrm{V}_{\mathrm{oj}}$ slide bearings used, is from 18 to $35 \mathrm{dm}^{3} /(\mathrm{kW} \cdot \mathrm{h})$. This value is correct when the motor has one crankshaft, whereas in the case of a newly designed OPE motor this expenditure has to be doubled due to the use of two crankshafts.

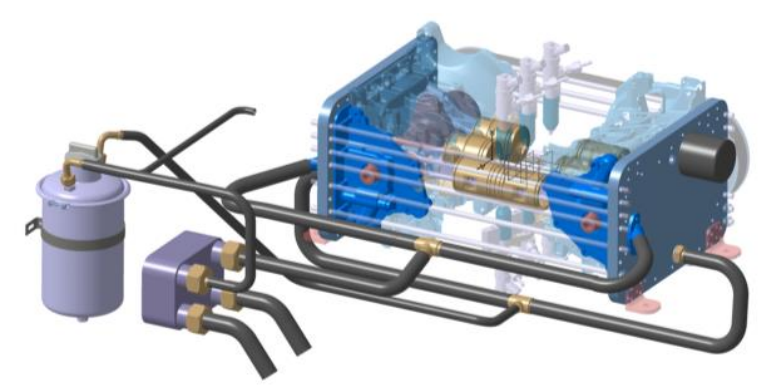

Fig. 1. External oil lubrication and cooling system OPE engine

\subsection{Analysis of automotive oil pumps}

The ideal pomp for the new type of engine was selected after analyzing oil pumps with a similar number of lubrication points and a similar theoretical flow rate, typically mounted in the modern diesel engines. The aim was to select an automotive oil pump for an aircraft engine capable of achieving the required flow rate of $80-100 \mathrm{dm}^{3} / \mathrm{min}$ at $4000 \mathrm{rpm}$. Such a flow rate is necessary because of two crankshafts, lubrication of the main gear and oil-sprayed piston surfaces to cool them. Three types of oil pumps of different rotor constructions and a similar flow rate were selected for our testing. Our research into flow rates will allow us to select the optimal pump construction for the OPE engine. Figures 2-4 show the pumps selected for the testing. The pumps have built-in oil pressure control valves.
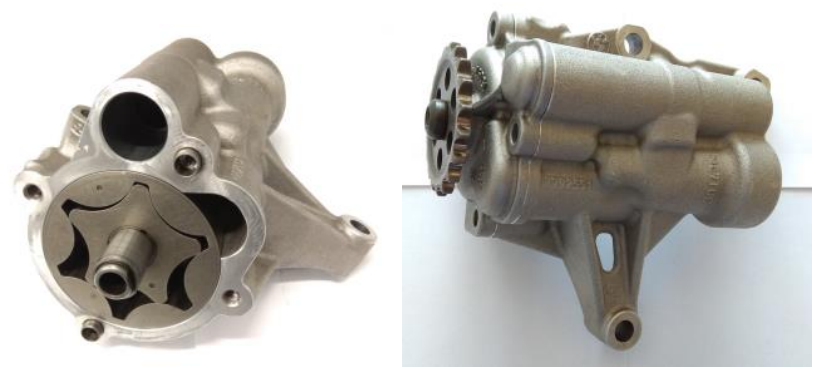

Fig. 2. Oil pump SdF, BMW M67TU D44
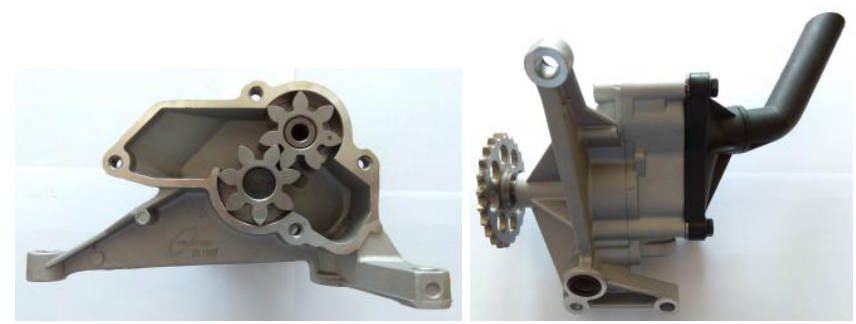

Fig. 3. Oil Pump Trucktec, Mercedes Sprinter 2.2 CDI

The Pierburg pump (Fig. 4), installed, for example, in the Nissan Patrol 2.8 TD, is a pump with variable flow rate.
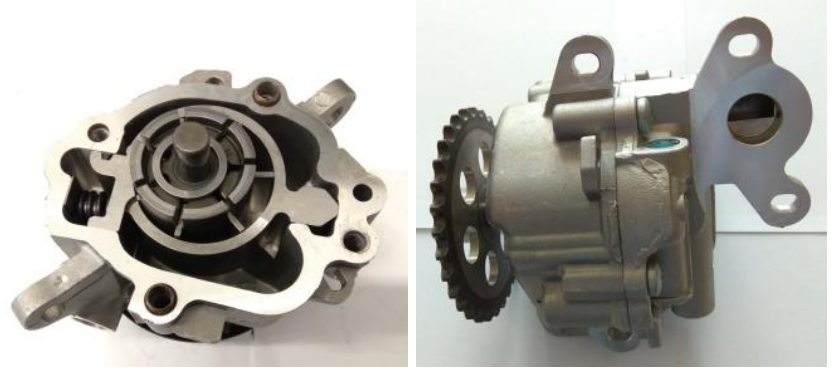

Fig. 4. Oil pump Pierburg, Nissan Patrol 2.8 TD

\section{Test stand}

Various types of oil pumps were tested on a special test stand where flow rates of each of the pump depending on temperature and oil pressure were measured. The pump are driven by the Tamel three-phase electric engine $(4 \mathrm{~kW})$ with an inverter capable of engine control to guarantee an enough power reserve to drive each of the pomp and to regulate pump speeds. The pumps are driven by a gearbox with a toothed belt. The gearbox consists of two HTD M8 gears with a geometric ratio of $1: 1.5$ or $1: 2$ (depending on the pump) and a $960 \mathrm{~mm}$-long and $20 \mathrm{~mm}$-wide toothed belt. The engine operation is stable over the entire speed range of a maximum value of $2880 \mathrm{rpm}$.

Figure 5 shows a diagram of the oil pump test stand. The Infineon KTY $19-6 \mathrm{M} / \mathrm{Z}$ temperature sensor and the Wika pressure tensiometer sensor were installed in the operating chamber of each of the oil pump. The volumetric flow rate was measured with the Badger Meter IOG 1" HF equipped with an impulser ILR740 flow meter measuring the flow rate from 5.7 to $170 \mathrm{dm}^{3} / \mathrm{min}$ with an accuracy of $0.5 \%$.

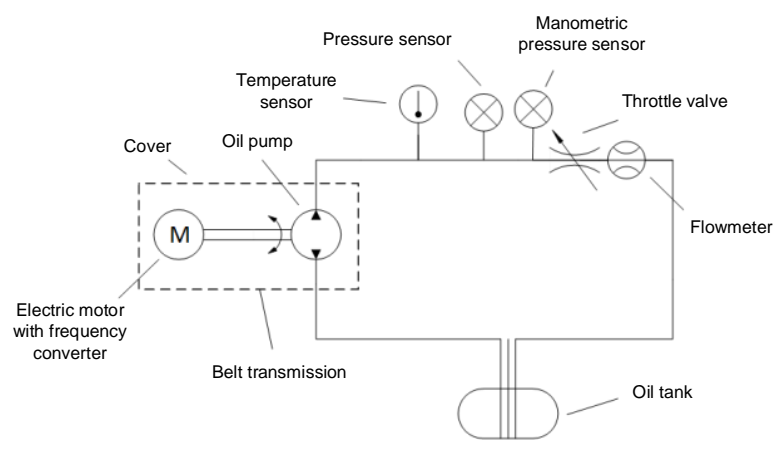

Fig. 5. Diagram of the pump test bench

The pump rotational speed was measured with a magneto-inductive sensor - Honeywell 1GT101. A 1 1/4 inch vol- 
umetric flow control valve was mounted at the outlet from the pump chamber. Figure 6 shows the oil pump test stand.

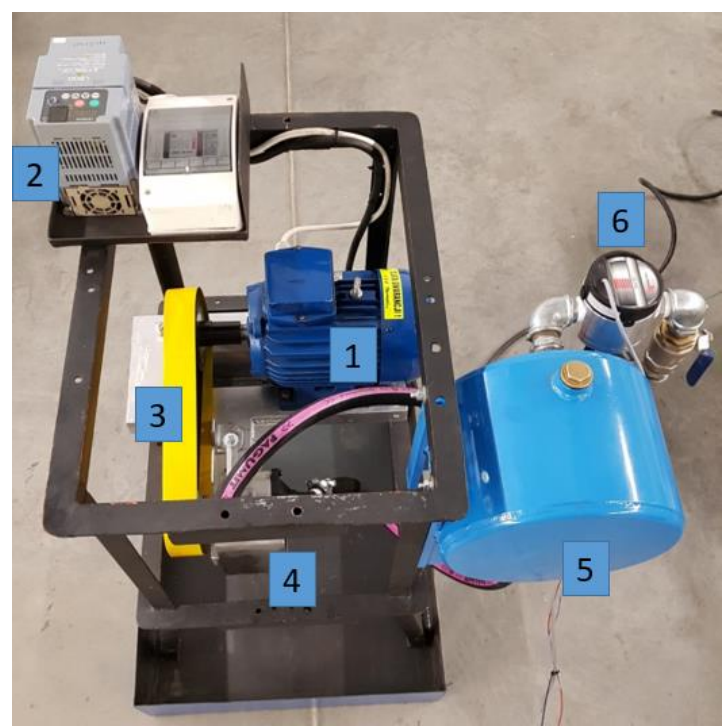

Fig. 6. Measuring station for oil pumps: 1 - electric motor, 2 - inverter, 3 - V-belt transmission with protective cover, 4 - oil pump with cover, 5 oil tank, 6 - flowmeter

\section{Test conditions}

The measuring points are specified by rotational speed and the degree of flow throttling given as the pressure in the system.

The tested parameters for these measuring points were: volumetric flow rate $\mathrm{Qv}(1 / \mathrm{min})$, pressure on the pomping side pt $(\mathrm{kPa})$ and oil temperature Tol $\left({ }^{\circ} \mathrm{C}\right)$. The engine speed was changed from 500 to $4500 \mathrm{rpm}$, every $500 \mathrm{rpm}$ by means of an inverter. Throttling was controlled by changing the position of the ball valve, which meant a change of (absolute) pressure from $100 \mathrm{kPa}$ to $700 \mathrm{kPa}$, every $100 \mathrm{kPa}$.

The tests were carried out at an ambient temperature of $22^{\circ} \mathrm{C}$ and an atmospheric pressure of $1010 \mathrm{hPa}$. The static pressure behind the $\mathrm{p}_{\mathrm{s}}$ pump was equal to the sum of the atmospheric pressure and the hydrostatic pressure measured from the column of liquid above the sensor. The tests were performed for four oil temperature values: $25^{\circ} \mathrm{C}, 40^{\circ} \mathrm{C}$, $60^{\circ} \mathrm{C}$ and $80^{\circ} \mathrm{C}$. The oil temperature for elevated values was stabilized by means of a heating system with an electric heater and a temperature stabilization system. $5 \mathrm{~W} 30$ oil was used for the tests.

\section{Test results}

The conducted tests of oil pumps used in lubrication systems of diesel engines enabled us to create flow rate characteristics for each of the pumps. Figures 7-9 show the selected results of the flow rates as a function of the rotational speeds of the pump rotor in relation to the pressure at a temperature of $80^{\circ} \mathrm{C}$.

The first tested pump was the SdF pump installed, e.g. in the BMW M67TU D44. It has the highest flow rate. The maximum flow rate at a speed of $4500 \mathrm{rpm}$ is about 105 $1 / \mathrm{min}$ when the pressure at the pomp outlet is equal to atmospheric pressure. The pump shows a relatively linear flow rate over the entire operating range, regardless of the oil pressure and temperature. For an oil temperature of $80^{\circ} \mathrm{C}$ and a pressure of $700 \mathrm{kPa}$, the maximum flow rate is $92 \mathrm{l} / \mathrm{min}$, which is less by approx. $13 \mathrm{l} / \mathrm{min}$.

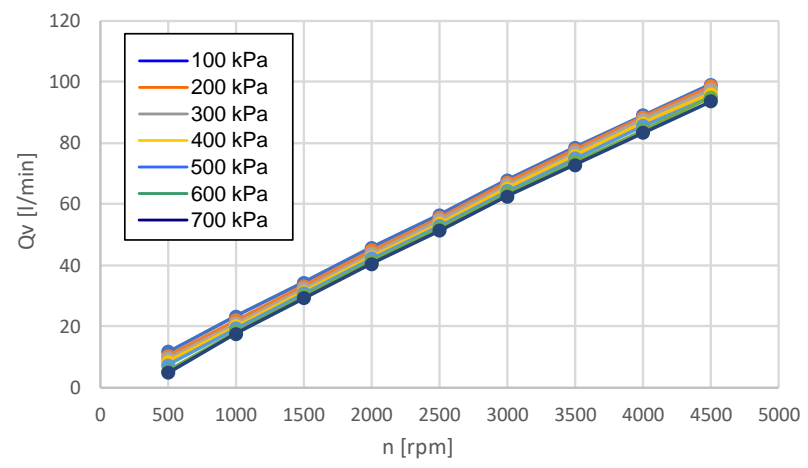

Fig. 7. Volume output as a function of speed for defined pressure values for SdF oil pump

Figure 7 shows the volumetric flow rate for the Pierburg pump as a function of speed. The measurements were without flow throttling for speeds ranging from $500 \mathrm{rpm}$ to 4500 $\mathrm{rpm}$. The obtained correlation of the flow rate and the pump speed is linear nearly in the entire speed range. The volumetric flow rate of the pump varies from 10 to $89 \mathrm{l} / \mathrm{min}$.

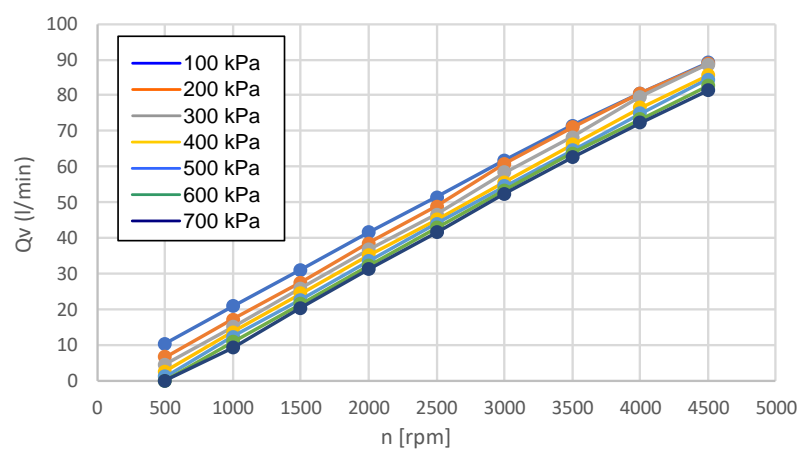

Fig. 8. Volume output as a function of speed for defined pressure values for Pierburg oil pump

The flow rate for the Trucktec pump (Fig. 8) for the pressure range of $100-500 \mathrm{kPa}$ is linear over the entire speed range of the pump rotor. The maximum flow rate is $78 \mathrm{l} / \mathrm{min}$ at a speed of $4500 \mathrm{rpm}$. When the oil pressure was increased depending on the speed, the pump flow rate changed a lot.

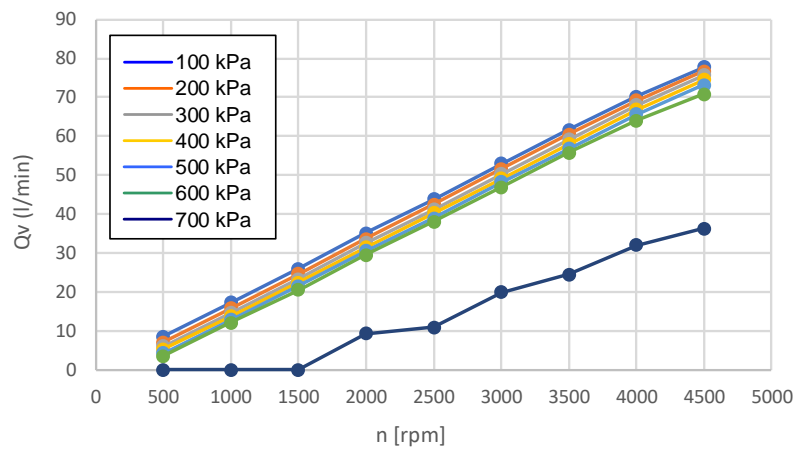

Fig. 9. Volume output as a function of speed for defined pressure values for Trucktec oil pump 
The pump generates a much lower flow rate at a pressure of $700 \mathrm{kPa}$, which is related with opening the bypass valve above $600 \mathrm{kPa}$.

Figures 10-12 show the dependence of the pump output on the rotational speed for different oil temperatures. In each case, an increase in the oil temperature caused a decrease in the oil pump output.

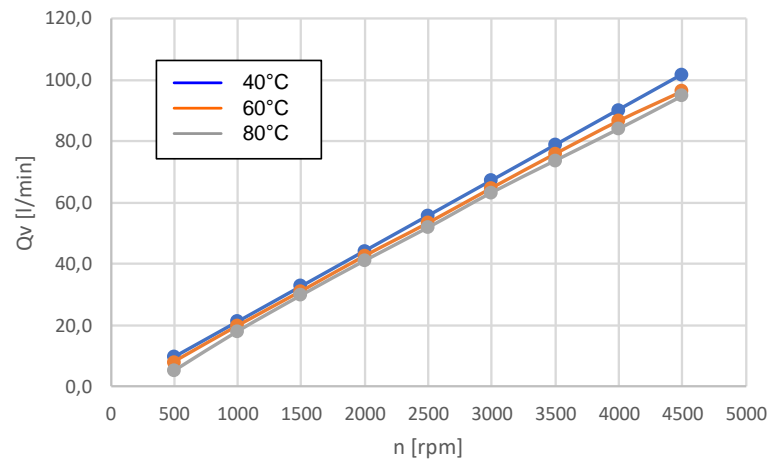

Fig. 10. Volume output as a function of speed at $600 \mathrm{kPa}$ and a defined temperature value for the BMW SdF oil pump

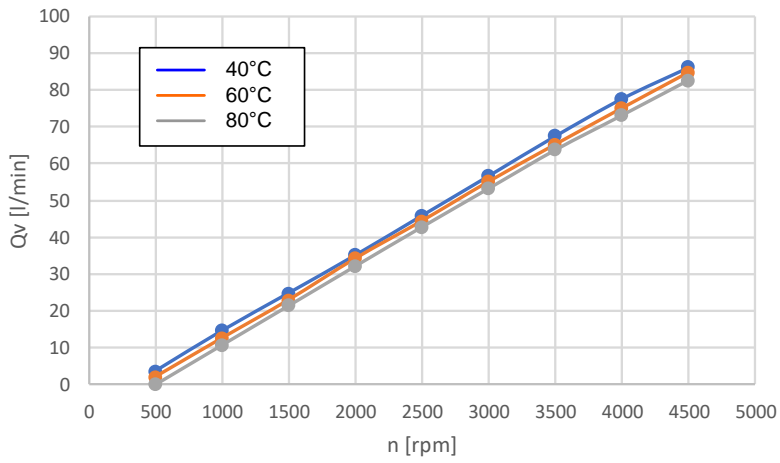

Fig. 11. Volume output as a function of speed at $600 \mathrm{kPa}$ and a defined temperature value for the Pierburg oil pump

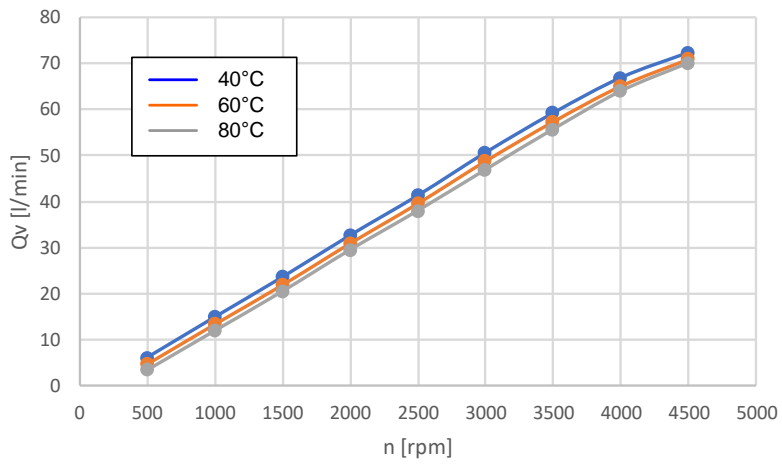

Fig. 12. Volume output as a function of speed at $600 \mathrm{kPa}$ and a defined temperature value for the Trucktec oil pump
The highest decrease was observed for the SdF BMW pump, about $7 \mathrm{l} / \mathrm{min}$, for other pumps this decrease did not exceed $3.5 \mathrm{l} / \mathrm{min}$.

Figure 13 presents a comparison of the flow of three tested pumps for oil pressure of $600 \mathrm{kPa}$ and temperature of $80{ }^{\circ} \mathrm{C}$. The SdF BMW SdF pump had the highest flow rate of $94 \mathrm{l} / \mathrm{min}$, while the Trucktec pump had the lowest flow rate. The difference was about 24 1/min.

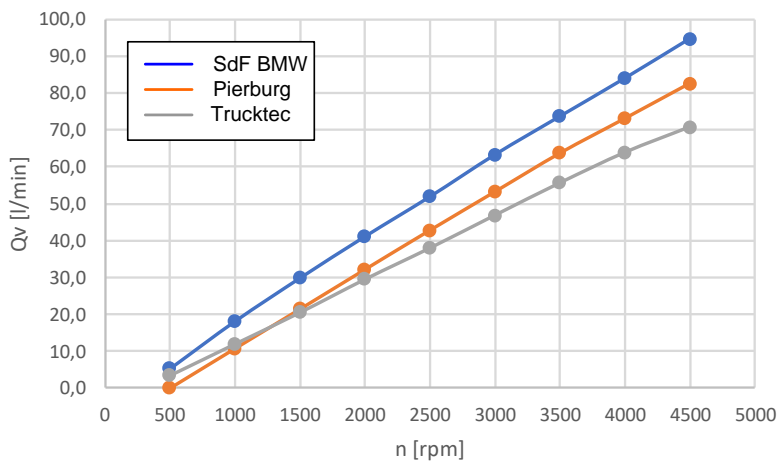

Fig. 13. Oil pump volume flow for $600 \mathrm{kPa}$ pressure and $80{ }^{\circ} \mathrm{C}$ oil temperature

\section{Summary}

The tests of the flow rates of the automotive oil pumps were to gain certain necessary data, i.e. changes in pressure, flow rate and the impact of oil temperature on flow rate and develop an assembly of pumps efficiently lubricating the OPE engine. The obtained results enabled us to create the characteristics of the pump operations. It was noticed that the flow resistance has a significant impact on pump's operating parameters, i.e. flow and pressure. The increased oil temperature decreased the pomp flow rates in each case. The maximal drop was $9 \%$ for the Trucktec pump. The obtained necessary data includes: data on the construction and operation of oil pumps, the maximum flow rates of each of the pump, operating pressure ranges, the correlation between pomp flow rates and pressures and temperatures for a given pump speed, and operating ranges for oil pressure control valves.

\section{Acknowledgement}

This work has been realized in the cooperation with The Construction Office of WSK "PZL-KALISZ" S.A." and is part of Grant Agreement No. POIR.01.02.00-00-0002/15 financed by the Polish National Centre for Research and Development.

\section{Nomenclature}

OP Oil pump

OPE Diesel Opposite Piston Engine

RPM Revolutions per minute

ICE Internal combustion engine
CI compression ignition

VFR Volumetric flow rate 


\section{Bibliography}

[1] FROSINA, E., SENATORE, A., BUONO, D. et al. A tridimensional CFD analysis of the oil pump of an high performance motorbike engine. Energy Procedia. 2014, 45, 938948.

[2] GITT GEHRKE, A., DUFFE, T., DING, H. Advanced simulation of the governing oil system of an engine. Stuttgart 2010.

[3] JIANG, Y., PERNG, C.Y. An Efficient 3D transient computational model for vane oil pump and gerotor oil pump simulation. SAE Technical Paper 70841, 1970.

[4] MOCILAN, M., HUSAR, S., LABAJ, J., ZMINDAK, M. Non-stationary CFD simulation of a gear pump. XXI Inter-

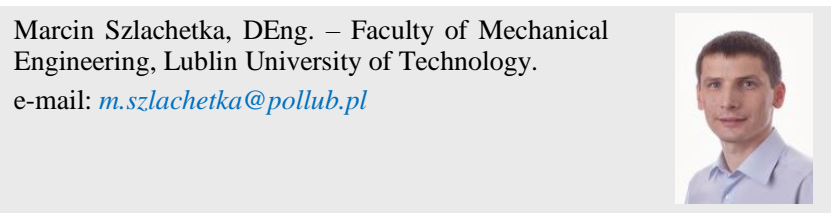

national Polish-Slovak Conference "Machine Modeling and Simulations 2016”. Procedia Engineering. 2017, 177, 532-539.

[5] ROSTEK, E., BABIAK, M., WRÓBLEWSKI, E. The influence of oil pressure in the engine lubrication system on friction losses. Procedia Engineering. 2017, 192, 771-776.

[6] WAJAND, J.A., WAJAND, J.T. Tłokowe silniki spalinowe średnio- i szybkoobrotowe. WNT. Warszawa 2005.

[7] ZHANG, D., PERNG, C.Y., LAVERTY, M. Gerotor oil pump performance and flow/pressure ripple study. $S A E$ Technical Paper 2006-01-0359, 2006.

Rafał Sochaczewski, DEng. - Faculty of Economic Sciences and Technology, The Pope John Paul II State School of Higher Education in Biala Podlaska. e-mail: r.sochaczewski@dydaktyka.pswbp.pl

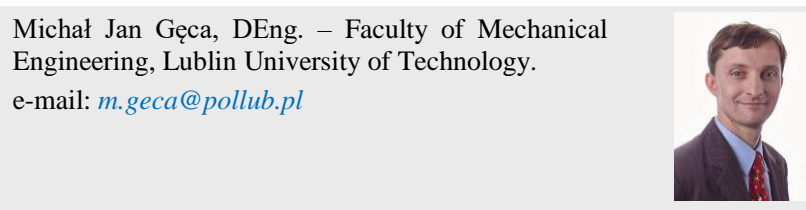

